\title{
Using Large Data to Analyze the Effect of Learning Attitude for Cooperative Learning between the High Achievement Students and the Low Achievement Students
}

\author{
Hsu Chia-Ling*, Chang Ya-Fung \\ Center for Teacher Education, Tamkang University, Taiwan
}

Copyright $\bigcirc 2017$ by authors, all rights reserved. Authors agree that this article remains permanently open access under the terms of the Creative Commons Attribution License 4.0 International License

\begin{abstract}
This study is to investigate the effect of the cooperation learning between the high achievement students and the low achievement students. Nowadays, the influences of the flipped classroom are all over the world in the secondary school education. Therefore, the cooperative learning becomes hot teaching strategies again. However, the learning attitude or the learning support may be different between the high achievement students and the low achievement students. The interested in the cooperative learning may be different between these two group students. We expect that the cooperative learning may be accepted by the high achievement students and the adaptive learning may be suit for the low achievement students too. This study used the secondary data to analyze the different between these two groups. The data is the secondary data which is from Taiwan Education al Panel Survey (TEPS) Data. We choose the 2014 Chinese part data set to analyze the effect of the cooperation learning between the high achievement students and the low achievement students. There were 8575 participates in 2014 Chinese data set. In order to analyze the difference from the high achievement students and the low achievement students, we choose the high 5\% students and low $5 \%$ students. Therefore, the total participates were 858 students include 429 high achievement students and 429 low achievement students. The result of the effect of cooperation learning between the high achievement students and the low achievement students is no significance difference. The result indicates that learning attitude of the high achievement students and the low achievement students in cooperation learning are no difference. In other words, the learning strategy in cooperation learning is fitting for the high achievement students and low achievement students in their learning attitude. Therefore, we can foresee that the flipped classroom especially using cooperation learning may successful in this education reform.
\end{abstract}

Keywords Learning Attitude, Cooperative Learning, Learning Achievement, Flipped Classrooms

\section{Background/ Objectives and Goals}

Recently, the flipped classroom is famous in the United States. In Japan, the collaborative learning is wildly spread in the whole country. Many different teaching strategies are used in Taiwan, such as Sharestar, MAPS, collaborative learning, e-learning etc. All these changes in education are turning around the learning, that is, the students take the place of the teachers in learning atmosphere. In other words, all these activities use cooperative learning in classroom. Although these flipped classrooms in Taiwan use cooperative learning, the strategies are different. The collaborative learning uses the group in two to four students in a group. The MAPS learning uses the group in four students and distinguishing the students into $\mathrm{ABCD}$ four levels. The e-learning uses one to one learning or group learning with the web platform. In this educational reform period, the cooperative learning is famous learning strategies in the secondary school learning.

All these education reform need to use group learning, the founder of the MAPS or Sharestar are the secondary teachers and they all announce that their method in teaching are very powerful. Moreover, they declare that the students learning achievement are improving with these new teaching methods. However, there is no research on these new methods which are required the cooperative learning in a group. Therefore, this study would like to explore the relationship with the group learning and the learning achievement.

From the point of Friedman's (2005) view that technologies, economics, and politics were affected each country, company, community and individual [1]. Therefore, many projects are ongoing in education, such as, "Every child matters in the curriculum" in England, "No child left behind" in the United States and "After school alternative program" in Taiwan [2] [3]. These projects focus on disadvantage students learning. Moreover, many educators discussed social justice in Indigenous Peoples, low achievement students, or new immigrants (Champagne, 2008; $\mathrm{Wu}$ and $\mathrm{Wu}, 2005)$ [4] [5]. So that, developing the 
proper curriculum for disadvantage and low academic achievement students are one of the important issues in nowadays.

The Ministry of Education in Taiwan promoted "Educational Priority Areas Program" to help the culture disadvantage school in enhancing the indigenous students' living and learning facilities [6]. Moreover, the "Potential Development Program" helped the indigenous students to explore their interests and then helped students entering high school or finding jobs. Nowadays, the "After School Alternative Program" emphasizes not only the indigenous students but also the culture disadvantage and low academic achievement students. This program integrates the school as well as the society resources. Some studies (Chueh, 2008; Chen, 2006) indicated that there were difficulties in implementation, such as, the source of students, the curriculum design and teaching materials [7][8]. In addition, conferences were hold to discuss the issue of helping disadvantage students' learning. Many studies reported the results and provided suggestions from different points of views. For example, Lee (2008) indicated that the supports from school administration were important and suggested that building a connection between junior high school and University as partnership were essential to success [9]. Hsu and Chang (2008) reported the effects of teaching team to remote areas to show that the resources from university were the college students who were in the teacher education program [10].

Some studies focused on the philosophy of curriculum development for disadvantage students. Yu (2008) mentioned that because of social justice the definitions of disadvantage students were important and the sources of students needed to be defined also [11]. Huang (2008) pointed out that many different factors caused low academic achievement; however, one main cause was the remote areas [12]. The statement was as the same as Contstantinos (2000), Entwisle \& Alexander (1988), and Gaziel (1997) [13][14][15].

E-learning requires integration between software and hardware and combination of technology and humanity. The application of technological media increases students' motivation for learning (Hsu \& Chang 2003) and keeps e-learning flourishing [16]. In the past, e-learning was provided through an asynchronous web-based classroom platform and the ADDIE model is heavily used in instructional design of e-learning (Hsu \& Kuo 2000; Hsu, She \& Lin 2000) [17] [18]. The present study also used the ADDIE model and text mining technology, which is gradually being applied to e-learning (Hsu 2005; Hsu, Wang, Hong \& Hsu 2006; Huang, Tsai \& Hsu 2006; Wang, Hong \& Hsu 2006) [19] [20] [21] [22]. Learners' homework can be collected via a web-based classroom platform, while text mining can help clarify learners' understanding levels of course contents, which deserves further investigation under e-learning theory (Hsu, Wang \& Hong 2007; Hsu \& Chang 2007) [23][24].

Graham (2002) suggests that in terms of team size, members of larger teams can better help each other with more internal resources [25]. This study applied these principles to form an e-learning instructors TT team. A team teaching model was applied to e-learning materials design and implementation. Thus, the study makes both academic and practical contributions. It is hoped that the results and retrospective thoughts derived from the study may help promote e-learning research theoretically and empirically in order to enrich theory and practice of e-learning.

The purpose of the flipped classroom is to help the students learn and improve their motivation. Many students and teachers are willing to use these strategies and showing the results of their teaching outcomes. However, there are a few studies report the outcomes especially in quantitative study. Although there were many cooperative learning studies indicated that the cooperative learning was a good method in classroom. Nevertheless, the flipped classroom using group is little difference in cooperative learning.

This study is to investigate the effect of cooperation learning attitude between the high achievement students and the low achievement students. The aim of this study is to find out whether there is a significant difference between the high achievement students and the low achievement students in learning attitude that may affect the cooperative learning. In another way, this study may supply the method how the high achievement students learn. We may use the high achievement student's learning attitude to help the low achievement students to improve their learning attitude in order to make the flipped classroom work more productively.

\section{Methods}

In this study we try to focus on the learning attitudes of learning skills in cooperation learning between the high achievement students and low achievement students. The reason is the learning attitudes and the learning skills can be learned by teaching from the instructors. In other words, the results may suggest some strategies to instructors who want to help the low achievement students. Moreover, these results may provide as remedial education program for educational administrator.

This study used the secondary data TEPS (Taiwan Educational Panel Survey) questionnaire to ask grade 8 students about their learning attitudes. The TEPS database is by the Academia Sinica, Ministry of Education and the National Science Council jointly planning a national survey of long-term plans. The repository is a questionnaire survey to collect information from States, high school, vocational, and college students. At the same time, these students as the core, to expand and to understand the most important of several factors that affect students' learning experience, such as, parents, teachers and schools. The item question, we choose to ask what their learning attitudes, was how the habit of their study in everyday for preparing their studies for 
cooperative learning from the TEPS questionnaire. This database contains so much information. As a result, we decided to choice only the year which are test in junior high school with grade 8 because of reducing the influence of the entry examination to senior high school.

The learning achievement, we choose, was the Chinese subject achievement test. In this test 30 multiple choice were provided. If the students answer the right answer, the student got one point. Therefore, the total high score was 30 . Although there were only 30 items in a test, there were 13 different tests to evaluate these students. Of course, these tests were produced by the experiences secondary school teachers. Moreover, the difficulty level of the 13 tests was at the same level.

The participants were randomly selected in Taiwan. Total valid questionnaires were 8575 . We selected the high 5\% achievement students and the low 5\% achievement students. Eight hundred and fifty eight students were selected including 429 high achievement students and 429 low achievements students.

The learning achievement was the Chinese subject achievement test. In this test 30 multiple choice were provided. If the students answer the right answer, the student got one point. Therefore, the total high score was 30 . Although there were only 30 items in a test, there were 13 different tests to evaluate these students. Of course, these tests were produced by the experiences secondary school teachers. Moreover, the difficulty level of the 13 tests was at the same level.

The procedure of this study as bellows

1. Literature review

2. Study the TEPS database questionnaire

3. Research topic determine

4. TEPS database question item Select

5. Data transform

6. Data analyze

\section{Results}

The aim of this study is to find out whether there is a significant difference between the high achievement students and the low achievement students in learning attitude that may affect the cooperative learning. The data analyze with SPSS 10.0. The table 1 shows the described statistic figure.

Table 1. Description of the samples

\begin{tabular}{|c|c|c|c|}
\hline Group & number & Male Female & Grade level \\
\hline $\begin{array}{c}\text { High achievement } \\
\text { Low achievement }\end{array}$ & 429 & 214215 & $8^{\text {th }}$ grade \\
\cline { 2 - 4 } & 429 & 214215 & $8^{\text {th }}$ grade \\
\hline Total & 858 & 428430 & \\
\hline
\end{tabular}

The result of t test shows in table 2 .
Table 2. T-test

\begin{tabular}{|c|c|c|c|c|}
\hline & number & average & $\begin{array}{c}\text { Standard } \\
\text { deviation }\end{array}$ & $p$ \\
\hline $\begin{array}{c}\text { High } \\
\text { achievement }\end{array}$ & 429 & 2.24 & .949 & \multirow{2}{*}{-.071} \\
\hline $\begin{array}{c}\text { Low } \\
\text { achievement }\end{array}$ & 429 & 2.25 & .979 & \\
\hline
\end{tabular}

$* \mathrm{p}<.05, * * \mathrm{p}<.01$

\section{Conclusions and Suggestion}

\subsection{Conclusions}

This study is to investigate the exploration of cooperation learning attitude between high-achieving students and low-achieving students. The aim of this study is to find out whether there is a significant difference between high-achieving students and low-achieving students in learning attitude that may affect the cooperative learning.

The result indicates that the high-achieving student's learning attitude is no significant difference and low-achieving student's learning attitude. This result is similar to the Benken, Ramirez, Li and Wetendprf (2015). The result indicates that there is no significant difference may cause by limitation of the test item number. Although there are many participants attending the test, the test items only contain 30 . Since the score range is not big enough, it is hard to separate high-achieving students and low-achieving students. This is the limitation of this study of using the secondary data, although this database is big data set, stand, and approve by the government.

\subsection{Suggestion}

Some suggestions are provided from this study.

The flipped classroom applies the cooperation learning strategies. This study investigates the effect of learning attitude between the high achievement students and low achievement students. The result indicates that there is no significant difference between these two groups. This result supports the MAPS group learning because the students' learning attitude is no significant difference. The high achievement student can help the low achievement student in the same group without any learning attitude difference. Moreover, the Sharestar approach is the same as the MAPS group learning. In others words, the flipped classroom with cooperation learning in Taiwan may make the difference in educational reform this time.

Some studies use the SEM method to analyze the factors indicating that many factors are related in learning achievement. However, this study uses the $t$ test to examine the difference between the high achievement students and low achievement students. More studies may need to cross check for the flipped classroom. Since this study uses the secondary large data to analyze the result, the result may different from the study with qualitative research. Therefore, the future studies are needed.

The suggestion to the teachers and educational administer 
is that promotion the flipped classroom is worth and may have a big successful in educational reform.

\section{Acknowledgements}

We would like to thank the school of Education in Tamkang University to support this study. Also, we like to thank the institution of TAST for release the data for this study to analyze in order to get the result.

\section{REFERENCES}

[1] Friedman, T. L. (2005). The world is flat: a brief history of the twenty-first century. New York, NY: Farrar, Straus and Giroux.

[2] No Child Left Behind Act of 2001 (2002). Public Law No.107-110.

[3] Ministry of Education (2006). After School Alternative Program.

2009/10/2http://163.19.64.10/handweb/data/files/200801110

545520.doc

[4] Champagne, D. W. (2008). Contemporary Education and Indigenous Peoples. The $14^{\text {th }}$ Annual conference of the Taiwan Association for Sociology of Education (TASE), Chia-yi County, 46-62.

[5] Wu, J. H., \& Wu, J. S. (2005). The study on the "new Taiwan children" educational necessaries and curriculum adjustment strategies. Journal of Curriculum and Teaching, 8(2), 53-72.

[6] Ministry of Education (2007). Promote Educational Priority Areas Program. 2009/10/2 http://163.25.130.2/advedu/download/96eduplan.doc

[7] Chueh, W. C. (2008). The Study of Lifelong Learning Key Competencies and Learning Self-efficacy for Junior High School Student in Yilan County Thesis, unpublished.

[8] Chen, M. J. (2006). The study of local administration with curriculum reform in constructing evaluation indicators, Education Policy Forum, 9(4), 181-205.

[9] Lee, S. C. (2008). Schools in remote areas of the practice care for vulnerable persons to share practical educational programs. Disadvantaged Students and Curriculum Programs and Effective Teaching Symposium, 47-56. Taipei: Tamkang University

[10] Hsu, C. L., \& Chang, Y. F. (2008). College Teaching-Team participating the curriculum planning and implementation to disadvantaged students. Disadvantaged Students and Curriculum Programs and Effective Teaching Symposium, 127-135, Taipei: Tamkang University.

[11] Yu, C. C. (2008). After-school programs to help disadvantaged students learn the planning and implementation. Disadvantaged Students and Curriculum Programs and Effective Teaching Symposium, 11-28. Taipei: Tamkang University.

[12] Huang, .R. J. (2008). In response to the needs of disadvantaged students in the design of teaching materials. Disadvantaged Students and Curriculum Programs and Effective Teaching Symposium, 29-45. Taipei: Tamkang University.

[13] Contstantinos, P. (2000). Internal and external factors affecting achievement in mathematics: Some findings from TIMSS. Studies in Educational Evaluation, 26(1), 1-7.

[14] Entwisle, D. R., \& Alexander,K. L. (1988). Factors affecting achievement test scores and marks of black and white first graders. The Elementary School Journal, 88(5), 449-471.

[15] Gaziel, H. H. (1997). Impact of school culture on effectiveness of secondary schools with disadvantaged students. The Journal of Educational Research, 90(5), 310-318.

[16] Hsu, C. L., \& Chang, Y. F. (2003). The study of ARCS model and the characteristics of educational media, Journal of Education Research, 116, 64-76.

[17] Hsu, C. L., \& Kuo, C. H. (2000). The Study of Web Material, the 2000 Conference on Web Learning Theory and Practice, Taiwan, 61-65.

[18] Hsu, C. L., She, H. C., \& Lin, M. S. (2000). The Web of Teacher Professional Development, 2000 International Conference on Computers in Education/ International Conference on Computer-Assisted Instruction 2000(ICCE/ICCAI 2000, Taipei, Taiwan, 1656-57.

[19] Hsu, C. L. (2005). Digging and Separating the Learner Opinions Utilizing KeyGraph Method, Paper present at The $3^{\text {rd }}$ Conference on Evolutionary Computation Applications and 2005 International workshop on Chance Discovery, Tamsui, December 3.

[20] Hsu, C. L., Wang, L. H., Hong, C. F., \& Hsu, F. C (2006). The KeyGraph Perspective in ARCS Motivation Model, the 6th IEEE International Conference on Advanced Learning Technologies, Kerkrade, Netherlands, 970-975.

[21] Huang, C. J., Tsai, P. H., \& Hsu, C. L. (2006). Exploring Cognitive Difference in Instructional Outcomes Using Text Mining Technology, the 2006 IEEE International Conference on Systems, Man, and Cybernetics, Taipei, Taiwan. 2116-2120

[22] Wang, L.H., Hong, C. F., \& Hsu, C. L. (2006). Closed Ended Questionnaire Data Analysis, KES2006 10th International Conference on Knowledge-Based \& Intelligent Information \& Engineering Systems, United Kingdom, 1-7.

[23] Hsu, C. L., Wang, L. H., \& Hong, C. F. (2007). Understanding Students' Conceptions and Providing Scaffold Teaching Activities, the 2007 International Conference of Teaching and Learning for Excellence, Tamsui, Taiwan, 166-174.

[24] Hsu, C. L., \& Chang, Y. F. (2007). The Action Research on Computer Technology in Teacher Educational Course, The Conference on Teacher Education Teacher Professional Development, Tamsui, Taiwan, 181-200.

[25] Graham, C. R. (2002). Factors for effective learning groups in face -to-face and virtual environments, The Quarterly Review of Distance Education, 3(3), 3078-319. 